\title{
Noise Source Identification for Ducted Fan Systems
}

\author{
Gareth J. Bennett* and John A. Fitzpatrick ${ }^{\dagger}$ \\ Department of Mechanical and Manufacturing Engineering, \\ Trinity College Dublin, Dublin 2, Ireland.
}

\begin{abstract}
Coherence based source analysis techniques can be used to identify the contribution of combustion noise in the exhaust of a jet engine and hence enable the design of noise reduction devices. However, when the combustion noise propagates in a non-linear fashion the identified contribution using ordinary coherence methods will be inaccurate. In this paper, an analysis technique to enable the contribution of linear and non-linear mechanisms to the propagated sound to be identified is reported. An experimental rig to study the propagation of noise through a rotor/stator set-up using a vane-axial fan mounted in a duct so that non-linear interactions between a sound source and the fan could be investigated is described. The technique which is used to identify a non-linear tone generated by the interaction of the rotor and a propagated tone is reported. The identification procedures are then applied to data from full scale turbo-fan engine tests instrumented with pressure transducers at the combustor can and in the hot-jet pipe with microphones in the near-field. At a particular power setting, the interaction between the combustion noise and the high pressure turbine was measured in the hot jet pipe. The analysis techniques enabled non-linear interactions to be identified and linear and non-linear coherent output powers to be determined.
\end{abstract}

\section{Nomenclature}

correlated part

\footnotetext{
* Lecturer.

${ }^{\dagger}$ Professor, Head of School.
} 
- conditioned or uncorrelated part

$\mathbf{R e}[]$ real part of []

$\pm m$ azimuithal mode order in the shaft and counter-shaft directions respectively.

$A_{m, n}(x)$ amplitude of the $(m, n)^{t h}$ mode

exit the exit plane of an aero-engine or a location in the hot-jet pipe

$f \quad$ frequency, $\mathrm{Hz}$

$f_{c} \quad$ upper frequency limit, $f_{c}=1 /(2 \Delta t)=f_{\text {samp }} / 2, \mathrm{~Hz}$

$f_{\text {samp }}$ sample rate, samples $/ \mathrm{s}, \mathrm{Hz}$

$G_{x x}(f)$ autospectral density function of $x(t)$

$G_{x y}(f)$ cross-spectral density function of $x(t)$ and $y(t)$

$H(f)$ frequency response function

$J_{m} \quad$ bessel function of the first kind of order $m$

$k_{r, m, n}$ transverse eigenvalue of the $(m, n)^{t h}$ mode or, the transverse wavenumber

$n \quad$ radial mode order

$n(t)$ extraneous noise

$p(t) \quad$ pressure signal

$T_{d}(i)$ record length of segment i

BPF blade pass frequency

C combustor

Comb combustor

COP coherent output power technique

F fan

HPT high pressure turbine

LPT low pressure turbine

M mach number

Np number of data points per segment

PSD power spectral density

$\mathrm{RP}[1,2, \mathrm{~B}]$ rumble probe $1,2, \mathrm{~B}$

$\mathrm{T}$ turbine

Subscripts

down downstream

up upstream

\section{Symbols}

$\Delta f \quad$ frequency resolution, $1 / T_{d}, \mathrm{~Hz}$

$\Delta t \quad$ sampling resolution, $1 / f_{\text {samp }}, \mathrm{s}$

$\gamma_{x y}^{2}(f)$ ordinary coherence function of $x(t)$ and $y(t)$ 
$\omega \quad$ frequency in $\mathrm{rad} / \mathrm{s}, \omega=2 \pi f$

$\Psi_{m, n}(r, \theta)$ eigenfunction of the $(m, n)^{t h}$ mode

Superscripts

+ incident

- reflected

\section{Introduction}

The reduction of the two principal sources of aero-engine noise, the fan and the jet, has resulted in a new noise floor being reached. This will limit the benefits to be gained by further reducing these dominant components, unless the noise sources which set this threshold are in turn reduced. Of these, combustion, or core noise, which is considered here to be the sum of combustion and turbine noise, is an area of current research activity. At relatively low jet velocities, such as occur at engine idle, during taxiing, and at approach and cruise conditions, core noise is considered a significant contributor to the overall sound level. It will continue to receive attention, as the current trend towards

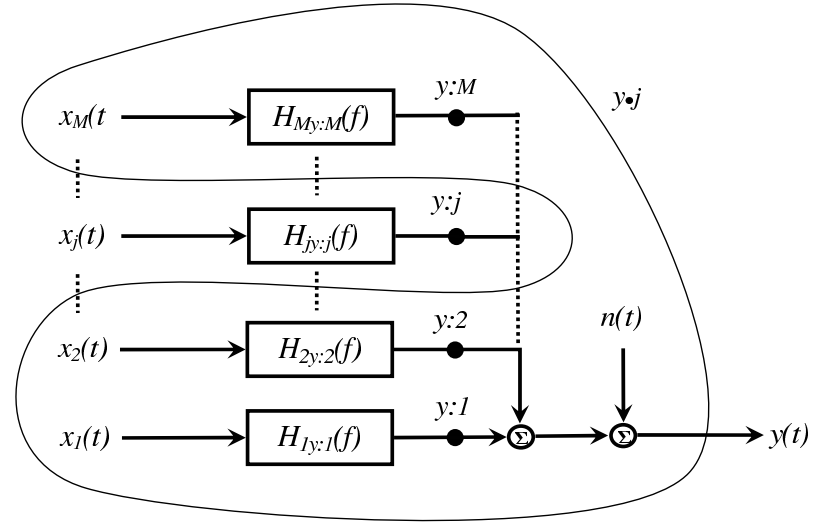

Figure 1. Multiple Source Acoustic Measurement high-bypass engines (which tend to reduce jet noise) and low Nox combustors (which may modify the noise characteristics) will result in core noise becoming a more significant source.

An acoustic measurement of a system of interest will most often be the summation of a number of separate acoustic sources along with some extraneous noise. For the case where it is not possible to remove individual sources without affecting the behaviour of the others, the challenge is to decompose the measurement signal into its constituent parts. For acoustic sources that are considered to be stationary random processes with zero mean and where systems are constant-parameter linear systems, figure 1, a multiple-input/single-output model, can be used to represent the system. The extraneous noise term, $n(t)$, accommodates all deviations from the model, such as additional acoustic sources which are unaccounted for. These deviations from the model can be a result of non-linear operations, non-stationary effects, acquisition, and instrument noise along with unsteady pressure fluctuations local to the sensor, such as flow or hydrodynamic noise. As the many acoustic noise sources in an aero-engine overlap in the frequency domain, with varying amplitudes, it can be difficult to 
quantify the individual contributions.

Coherence-based noise source identification techniques can be used to identify the contribution of combustion noise to near and far field acoustic measurements of aero-engines. Karchmer and Reshotko ${ }^{1,2}$ and Reshotko and Karchmer ${ }^{3}$ used the ordinary coherence function between internal measurements and farfield microphones and derived the core noise at farfield locations by calculating the coherent output power (COP): a technique reported initially by Halvorsen and Bendat ${ }^{4}$. Karchmer ${ }^{5}$ also used the conditioned coherency function to determine where the source region for core noise was located. Extraneous noise contamination at an internal microphone location can result in the derived core noise at the farfield location being significantly lower than the true value. For such situations, Shivashankara ${ }^{6,7}$ used Chung's ${ }^{8}$ flow noise rejection technique, to identify the internal core noise contribution to farfield noise measurements. Hsu and Ahuja ${ }^{9}$ extended Chung's technique to develop a partial-coherence based technique, that uses five microphones, to extract ejector internal mixing noise from farfield signatures which were assumed to contain the ejector mixing noise, the externally generated mixing noise, and also another correlated mixing noise presumably from the ejector inlet. Wherever there is more than one source, all of these approaches necessitate the location of at least one sensor near one of the sources, e.g. the core noise source, in order to measure that source in isolation. Where there is only one source in the presence of extraneous noise, it has been shown when using Chung's technique, that no direct measure of the source is necessary. Minami and Ahuja ${ }^{10}$ discuss a technique where only farfield measurements are needed to separate any number of correlated sources from extraneous noise, which due to its distributed nature, could be jet noise for example. Previously published work in this area from the 1970's and 1980's has been revisited in more recent years by Hsu and Ahuja. ${ }^{9}$ In Bennett and Fitzpatrick, ${ }^{11}$ techniques which can be used to identify the contribution of combustion noise to near and far-field acoustic measurements of aero-engines have been evaluated.

The coherence based source analysis techniques above can be used to identify the contribution of combustion noise in the exhaust of a jet engine and hence enable the design of noise reduction devices. However, when the combustion noise propagates in a non-linear fashion the identified contribution using ordinary coherence methods will be inaccurate. In this paper, an analysis technique to enable the contribution of linear and non-linear mechanisms to the propagated sound to be identified is reported. The technique is then applied to data from a small scale rig and to data from full scale turbo-fan engine tests. 


\section{Non-linear Analysis}

The coherence function $\gamma_{x y}^{2}(f)$ of two quantities $\mathrm{x}(\mathrm{t})$ and $\mathrm{y}(\mathrm{t})$ is the ratio of the square of the absolute value of the cross-spectral density function to the product of the auto-spectral density functions of the two quantities:

$$
\gamma_{x y}^{2}(f)=\frac{\left|G_{x y}(f)\right|^{2}}{G_{x x}(f) G_{y y}(f)}
$$

For all $f$, the quantity $\gamma_{x y}^{2}(f)$ satisfies $0 \leq \gamma_{x y}^{2}(f) \leq 1$

As discussed in Bendat and Piersol ${ }^{12}$ page 172, for example, the situation where the coherence function is greater than zero but less than unity may be explained by one of the following three possible physical situations.

- Extraneous noise is present in the measurements.

- The system relating $\mathrm{x}(\mathrm{t})$ and $\mathrm{y}(\mathrm{t})$ is not linear.

- $\mathrm{y}(\mathrm{t})$ is an output due to an input $\mathrm{x}(\mathrm{t})$ as well as to other inputs.

The underlying assumption with the identification techniques reviewed by Bennett and Fitzpatrick, ${ }^{11}$ is that the propagation path, from upstream of the turbine to a downstream measurement point, is a linear one. That is to say, to assume that a decrease in coherence is to be attributable to only the first and third of the above situations, is to ignore the possibility of a non-linear system.

A drop in coherence between combustion noise measurements made at the combustor can with pressure transducers and microphone array measurements focused on the exit plane of an aero-engine, when the rpm of the engine was increased, was reported by Siller et al. ${ }^{13}$ An interpretation of this result is that, when the jet noise is low for low engine power settings, the core noise is a significant contributor to noise in the near-field. However, as the jet noise becomes more significant, the coherence drops due to the relatively low contribution of the combustion noise. This rationale assumes a linear frequency response function between the combustion can and the exit plane of the engine. It is also possible that the reduction in coherence is due to non-linear interactions as the unsteady pressure from the combustor passes through the rotor/stator stages. This paper examines the scenario where a fluctuating pressure is modified, in a non-linear sense, as it propagates through a rotor/stator stage.

Acoustic interaction between rotors is a common observation in turbo-machinery noise measurements and has been discussed analytically by Cumpsty, ${ }^{14}$ Holste and Neise, ${ }^{15}$ Enghardt et al. ${ }^{16}$ and numerically by Nallasamy. ${ }^{17}$ Energy at two different frequencies may interact to induce energy at a third. In these situations, the upstream energy source is a 
rotor-stator pair whose excited spinning modes impinge upon a second rotor. However, the case where broad band or narrow band noise, such as may originate from a combustor, interacts with a rotor-stator pair, (e.g. turbine noise), producing noise at sum and difference frequencies, is a relatively unexplored area. Evidence of this phenomenon is presented in the paper and the process is thought to be analogous with the theories reported Cumpsty ${ }^{14}$ and Moore ${ }^{18}$ i.e., acoustic energy from the combustor propagates down the duct as a spinning mode which subsequently interacts with a downstream rotor.

The non-linear analysis of this paper investigates how to accommodate, in addition to propagated combustion noise and turbine noise measured at the exit plane of an aero-engine, the possibility of an interaction between the upstream combustion noise and the turbine, as outlined in figure 2. What is suggested is that the additional inputs into the system due to non-linearities could be an alternative cause for the drop in coherence with increasing engine speed as measured by Siller et $a l^{13}$ and not simply the relative decrease in importance of the combustion noise compared to the other linear terms. As will be seen in the following simulations, quite the opposite could be true. In a non-linear system, a drop in coherence with increasing engine speed could occur when there is no relative change in power of the linear noise sources. This may lead to the incorrect conclusion that combustion noise is less significant and may, as a result, be ignored in the development of acoustical treatment. It is demonstrated how the effect is similar to a non-linear quadratic operation being performed on the sum of the two noise sources.

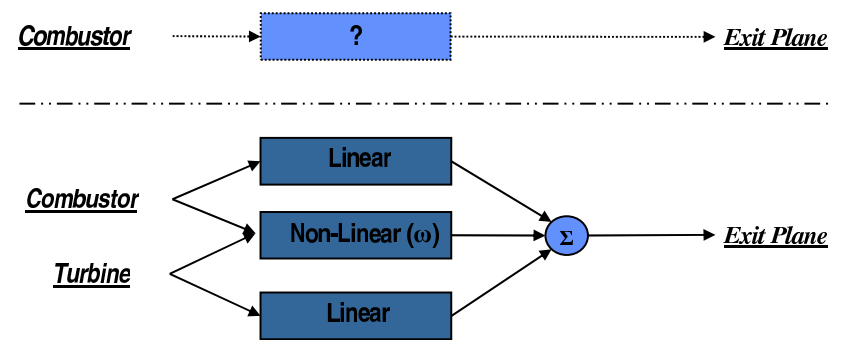

Figure 2. Frequency response function between the combustion noise and the pressure measured at the exit plane when some rpm dependent non-linearity is included in the model.

\section{A. Non-linear Simulations}

In order to investigate the influence of the non-linear interactions, a series of simulations were performed using synthetic data. A common non-linear interaction is quadratic in nature resulting in sum and difference frequencies as well a doubling in frequency. This can be demonstrated by observing the following two trigonometric identities.

6 of 26

Dr. G. Bennett and Prof. J. Fitzpatrick 


$$
\begin{aligned}
{[A \cos (\omega t)]^{2} } & =\frac{1}{2} A^{2}[1+\cos (2 \omega t)] \\
{\left[A \cos \left(\omega_{1} t\right)+B \cos \left(\omega_{2} t\right)\right]^{2} } & =\frac{1}{2} A^{2}\left[1+\cos \left(2 \omega_{1} t\right)\right]+\frac{1}{2} B^{2}\left[1+\cos \left(2 \omega_{2} t\right)\right]+A B \cos \left(\omega_{1}+\omega_{2}\right) t+A B \cos \left(\omega_{1}-\omega_{2}\right) t
\end{aligned}
$$

The doubling of frequency arises from self interaction, whereas the sum and difference frequencies come about from combination interactions.

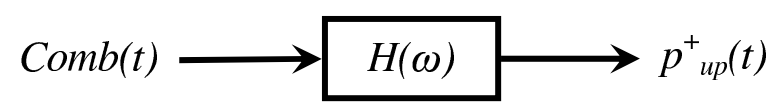

(a) Incident pressure upstream, $p_{u p}^{+}(t)$

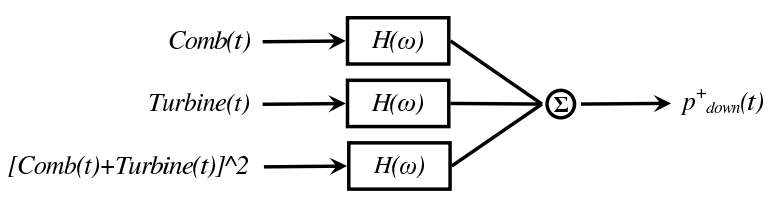

(b) Incident pressure downstream, $p_{\text {down }}^{+}(t)$

Figure 3. Incident pressure models accommodating a quadratic non-linear term.

For the simulations of an aero-engine, figure 3 shows the input models for upstream and downstream of the turbine, where it is assumed in this figure that incident sound only is measured. The synthetic data was generated in Matlab using filtered statistically independent random data signals. Figure 4(A) shows the basic simulation. This is the low power case, i.e. in its frequency range, combustion noise is greater than jet noise. In addition to the linear input terms of figure 3, viz. tonal turbine noise and low frequency band limited combustion noise ${ }^{a}$, the exit plane measurement of an aero-engine is simulated to contain broad band jet noise. Figure 4(B) shows the simulated non-linear quadratic input $\left(G_{\text {comb }}+G_{\text {turbine }}\right)^{2}$ in addition to the others. An important point to be noticed here, is how due to the frequency interactions, significant energy is created at frequencies where the energy of the linear terms is quite low. Row 2 of this figure shows the sum of the exit plane components representing an exit plane measurement, and the combustion noise only representing an upstream measurement. Row 3 plots the coherence between these latter two, i.e. the combustion noise and the total noise. It is shown how for this low power case, the coherence is quite high. For the higher frequencies the coherence drops off as the contribution of the upstream combustion noise to the exit plane measurement at these frequencies is negligible.

Figure 5 plots the same information for the high power case. In column one all three inputs increase by the same amount, relative to column one of figure 4, which results in no change to the coherence. In column 2, the turbine noise and combustion noise increase by the same amount as in column 1 , but the jet noise increases by relatively more. The coherence is seen to drop here, due to the relative decrease in contribution of the combustion noise to the total noise. This is the "linear" interpretation of the data presented in Siller et al. ${ }^{13}$

\footnotetext{
${ }^{a}$ Combustion noise is generally limited to a frequency range below $800 \mathrm{~Hz}$ and typically peaks in the $200-500 \mathrm{~Hz}$ region. However, for reasons of clarity, this range is increased in these figures.
} 

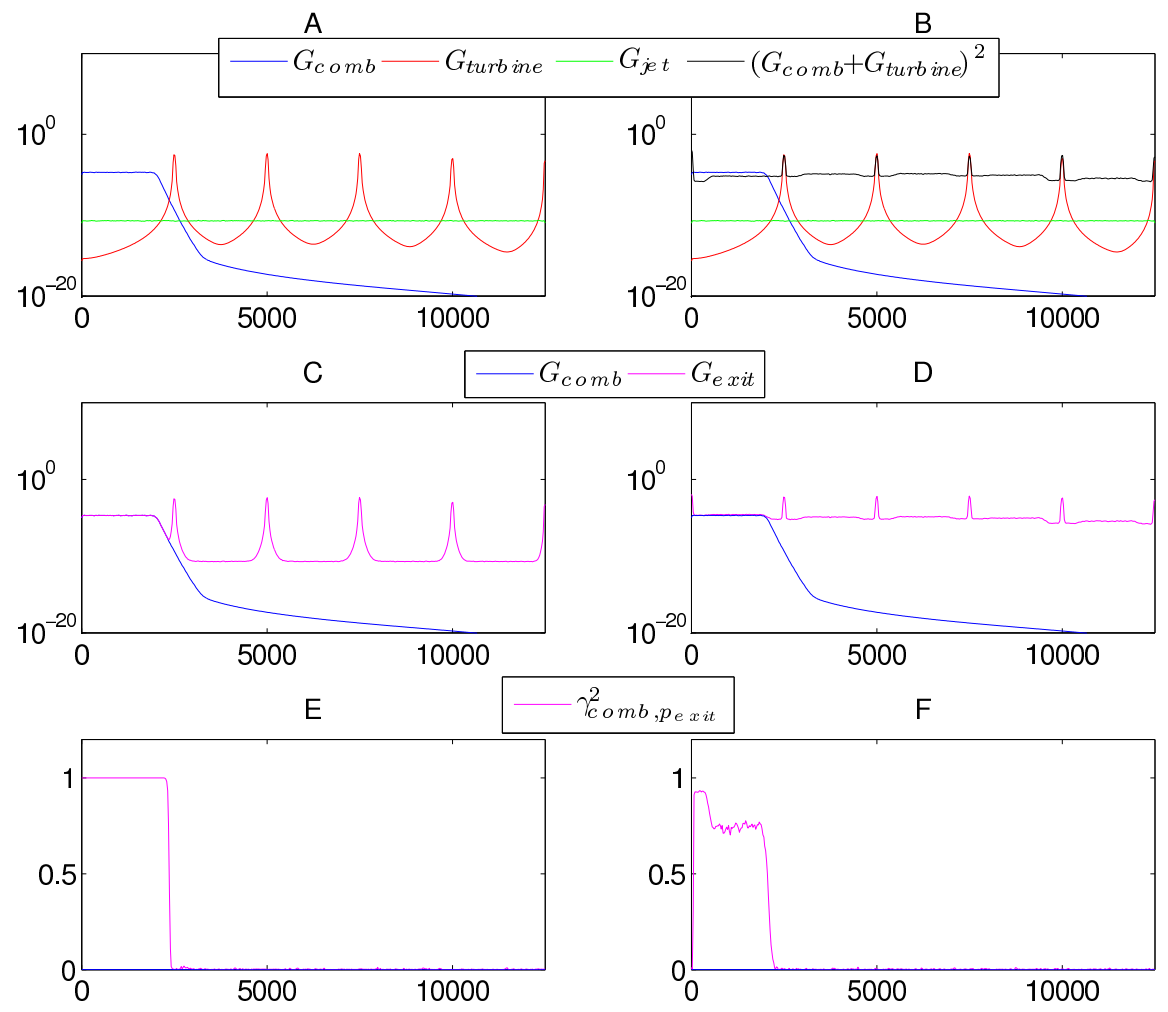

Figure 4. Combustion Noise, Turbine Noise and Jet Noise simulation at a low power setting. Column 2 contains a non-linear quadratic interaction term.

Column three shows the same increase in power of the three linear terms as in column 1 but in this case, due to the non-linear nature of the quadratic term, it increases relatively more, causing it to dominate, which results in the drop in coherence. It is therefore the presence of the non-linearity that causes the drop in coherence and not a decrease in the combustion noise relative to the other linear terms.

Given these two latter scenarios, viz. 1.) three linear terms only, where the jet noise is relatively higher than the combustion noise in that frequency range, and 2.) three linear terms, with the combustion noise being highest apart from the non-linear term in that frequency range, figure 6 may now be addressed. From observation of the second row, the total pressure measured is similar for the two cases, i.e., tonal harmonics with a broad band noise floor. To insert a core liner aft of the turbine in the first scenario will have little effect for this high power case as the jet noise is dominant and is created beyond the exit plane. In the second case however, there is a benefit to be gained, as the low frequency noise is generated upstream of the exit plane and can be attenuated by the liner. Even greater noise attenuation may be attained by reducing the combustion noise (or turbine noise) at source in the presence of a non-linear system which couples the two. By eliminating the combustion noise at source, its contribution will not only disappear from its low frequency range but also from higher interaction frequencies. In column 1 we see little benefit from eliminating 

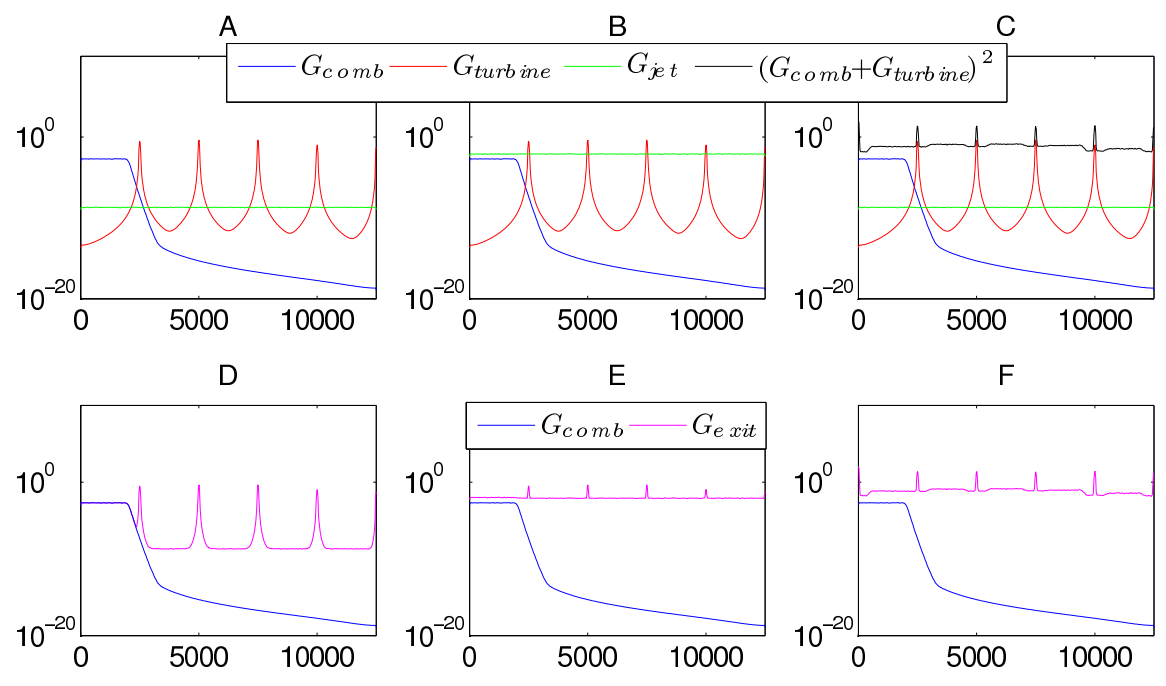

G
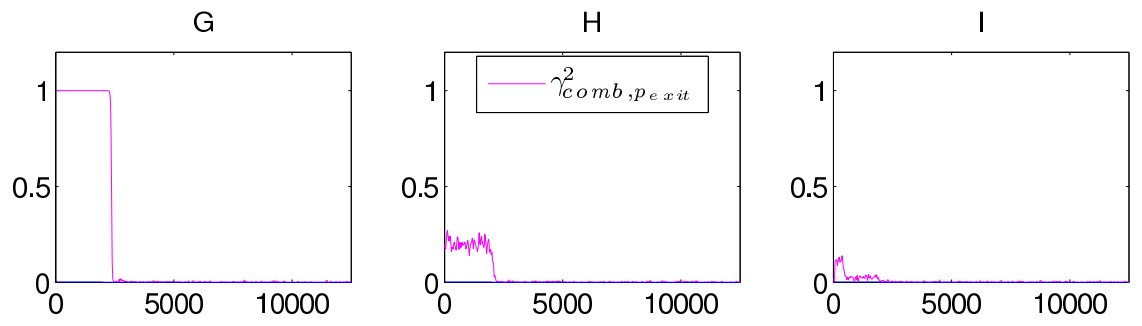

Figure 5. Combustion Noise, Turbine Noise and Jet Noise simulation at a high power setting. In column 1, all three components have been increased by the same amount. In column 2 , combustion and turbine noise have been increased the same a mount as column 1 but jet noise by relatively more. In column 3 , the linear inputs are increased the same amount as in column 1. 
the combustion noise where jet noise dominates. This figure highlights the benefits to be gained by combustion noise reduction in the presence of a non-linear interaction, but also how important it is to be able to identify the non-linear process as incorrect deductions can be made without knowledge of its presence.

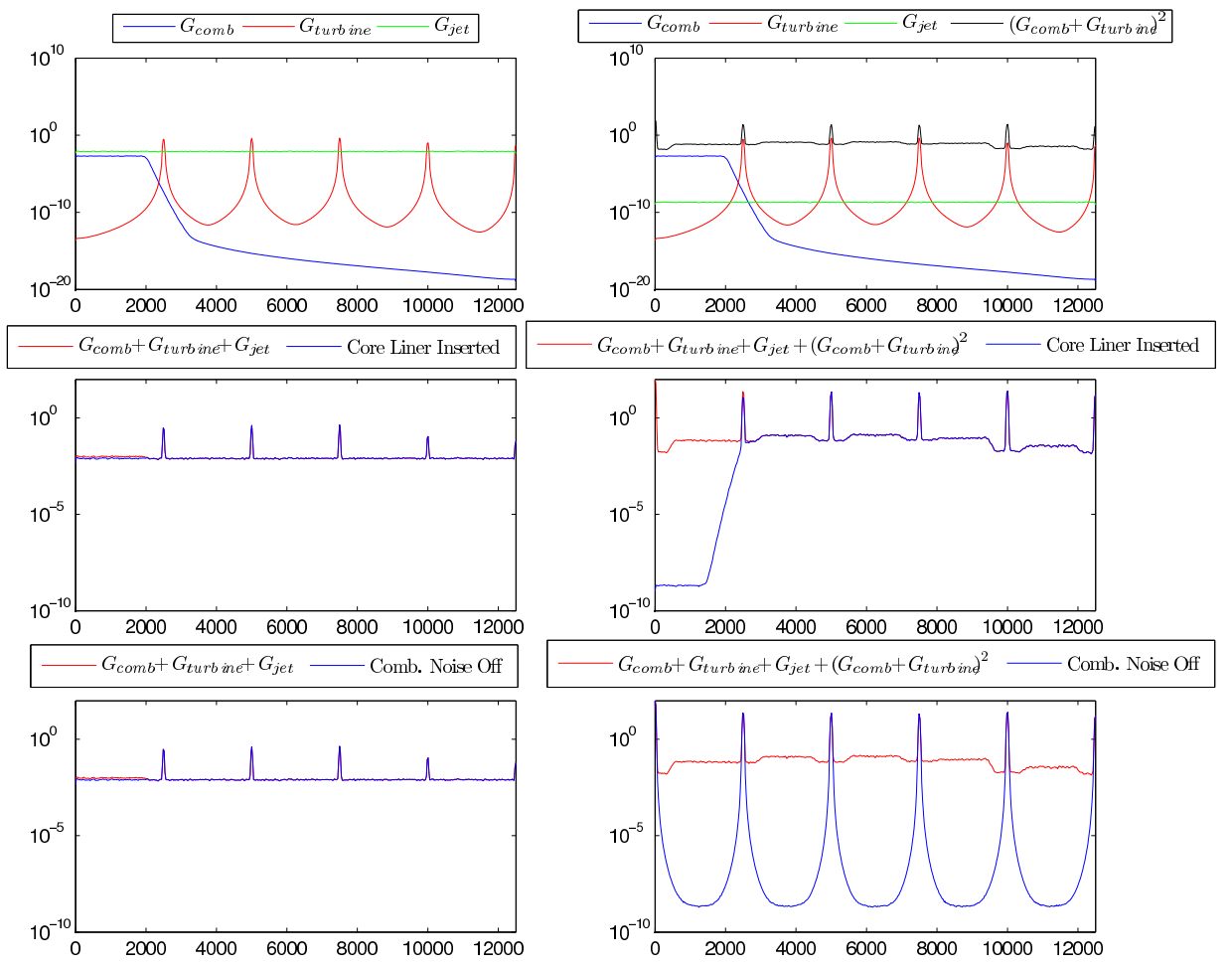

Figure 6. Comparison of the two scenarios. The total exit plane pressure is similar in both cases. However, in the first case Jet Noise dominates whilst in the second case it is the non-linear term which is greatest.

A second set of simulations were performed with narrow band noise for the combustor instead of the low frequency band limited noise used in the previous simulations. Jet noise is omitted from these simulations to simplify the analysis. It can be seen readily in figure 7(B) how the non-linear term is made up of double frequencies as well as sum and difference tones.

From figure 7, it can be seen that if the COP technique was used between the combustion noise only and the total noise, then the only contribution to the total noise made by the combustor would be identified as being low frequency narrow band noise. The coherence for this case is shown in figure 8 (A.). For a non-linear process this would be an incorrect deduction, however, as the combustor also contributes to the total noise at all the higher interaction frequencies. Without close inspection and measurement, the higher interaction frequencies could be mis-interpreted as rotor-stator interaction noise, particularly for aeroengines with many blades and vanes over many stages.

Figure 8 (B.) shows the coherence for the "ideal" situation for identification where the 

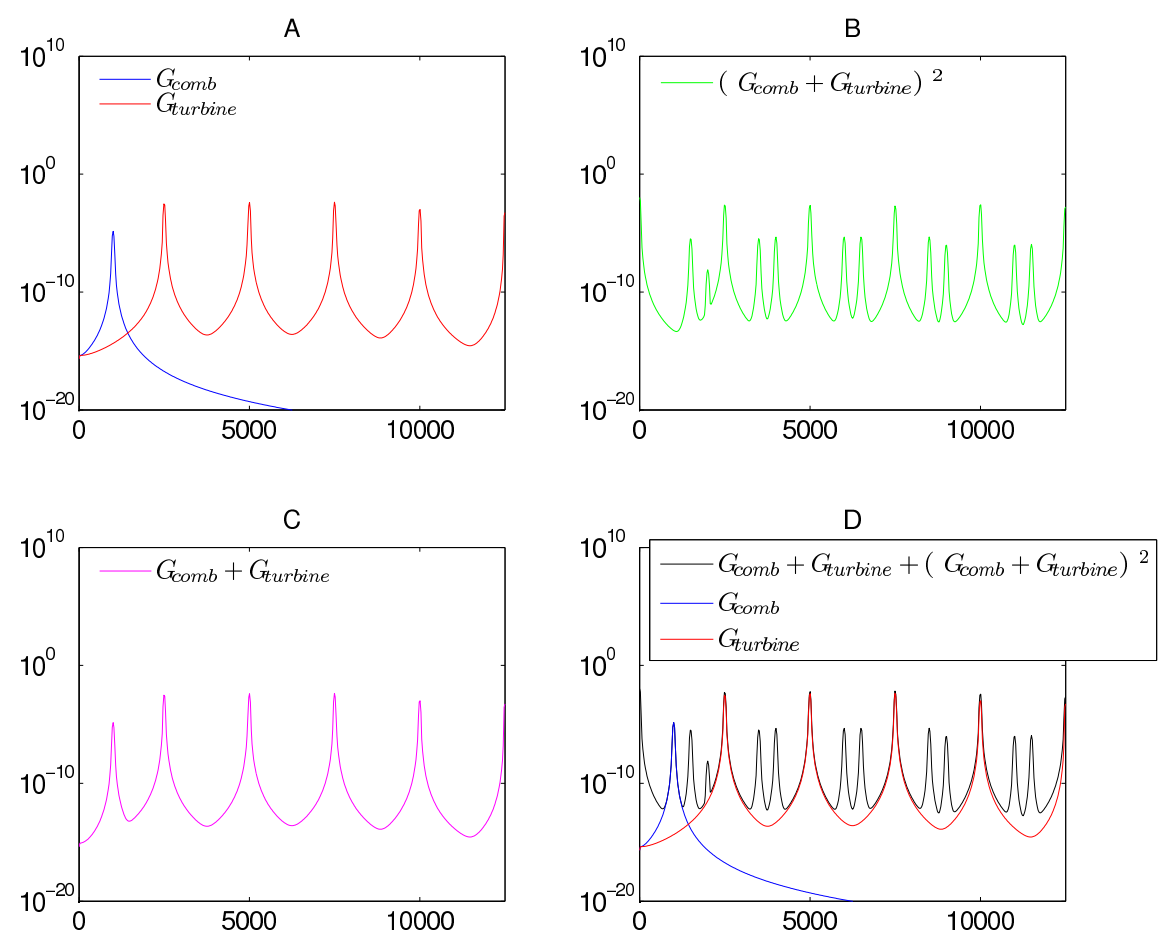

Figure 7. Narrow band combustion noise simulation. Plot A shows the linear sources, viz. the combustion noise and the turbine noise. Plot $\mathrm{C}$ shows the linear summation of these. Plot B shows the non-linear interaction term (if present) and plot D shows a downstream measurement when non-linear interaction has taken place.

upstream contribution of the combustor and turbine only can be measured. For this case, drop-outs or a reduction in the coherence is attributable to the additional non-linear term. When other valid terms are present in the downstream measurement e.g. jet-noise, hydrodynamic noise or other acoustic "linear" sources, the coherence in figure 8 (B.) will also drop. In order to identify the non-linear terms more directly, assuming a quadratic interaction, the coherence between the square of the combustor and turbine contributions can be formed in the time domain and the coherence between this and the downstream measurement determined, as is shown in figure 8 (C.)

In practical situations, a measurement of the combustor noise and turbine noise in isolation is not always available in the presence of non-linear interactions. In this paper a technique is developed where the non-linear contribution is measurable even when the turbine and non-linear contributions are propagated to the upstream measurement location.

\section{B. Experimental Set-up}

An experimental rig was designed to examine the propagation of noise through a rotor/stator set-up, and is shown schematically in figure 9. The speaker represents the source noise which is directed down a brass tube of $3 \mathrm{~mm}$ wall thickness with an internal diameter of $0.051 \mathrm{~m}$. This end of the tube is open and allows air to be drawn into the pipe by the vane-axial 

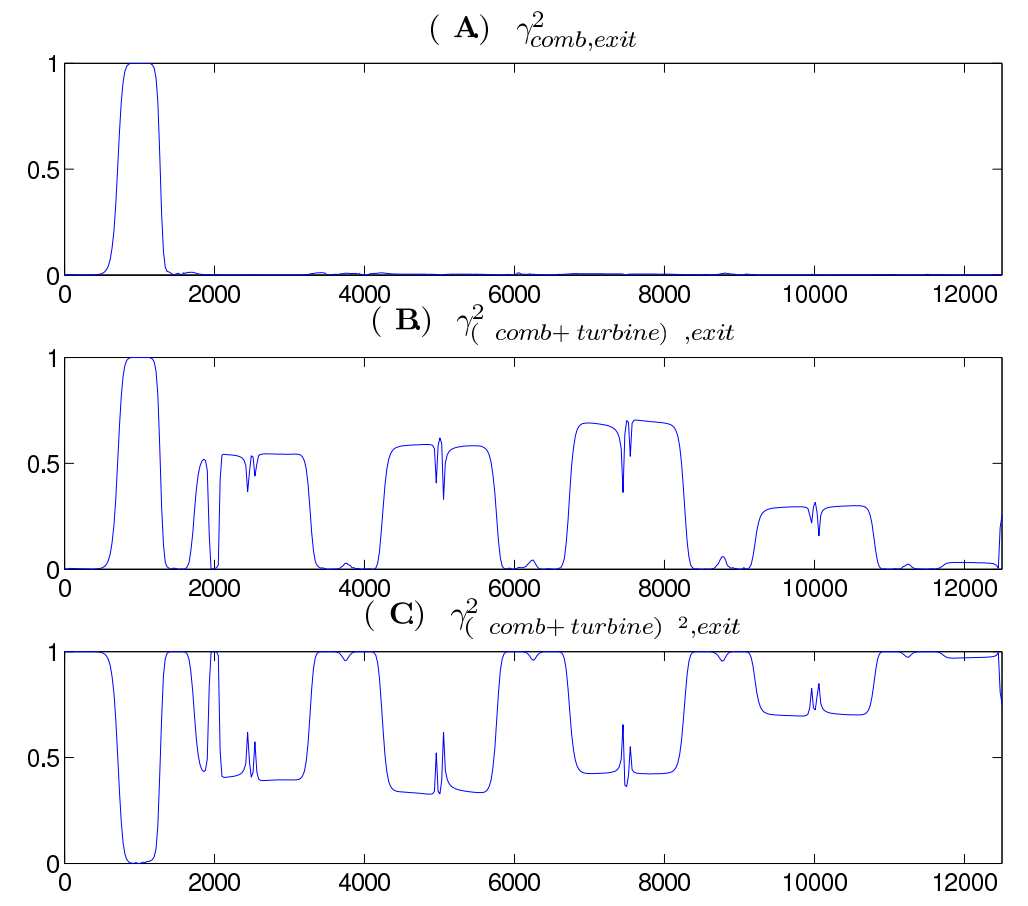

Figure 8. The coherence function plotted for three different situations. A. between the combustor measurement and the exit plane measurement, B. between an upstream measurement of the combustor and turbine only noise, and C., between the square of the upstream "linear" components.

fan situated at a minimum of $1.2 \mathrm{~m}$ from the entrance, according to the test set-up. This vane-axial fan which has a single 8 blade rotor stage downstream of a single 5 vane stator stage represents a simplified turbine of the turbofan engine. The tube end is fitted with an open anechoic termination designed to reduce flow expansion/separation noise as well as reflections. Microphones mounted flush with the inside of the pipe can be located upstream and downstream of the fan, at various axial and circumferential positions. Additional microphones can also be located in the near-field at the exit plane. Also illustrated, $s(t)$, is electrical signal to the speaker. This can be recorded with a view to using this signal to condition the measured pressures if necessary.

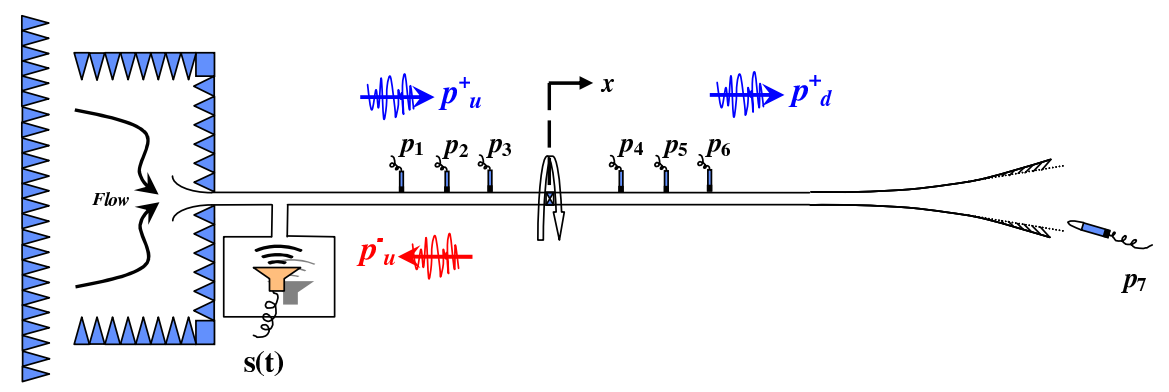

Figure 9. Schematic of Experimental Rig

A 32 channel data acquisition system was used to acquire the data. This consisted of 12 of 26

Dr. G. Bennett and Prof. J. Fitzpatrick 
2 X 16 bit simultaneously sampling Kinetic Systems V200 cards mounted into a National Instruments chassis. A PC running LabView, was used via a National Instruments PCI card to acquire the data from the National Instruments MXI controller card in the chassis. All data, once acquired into time domain files by LabView, were subsequently processed using Matlab.

Table 1. Spectral estimate parameters

\begin{tabular}{lc}
\hline \hline Parameter & Value \\
\hline Segment length, i.e., data points per segment, $N p$ & 1024 \\
Sample rate, $f_{\text {samp }}$, samples $/ \mathrm{s}$ & 25,000 \\
Segment length, $T_{d}=N p / f_{\text {samp }}, \mathrm{s}$ & 0.04096 \\
Sampling interval, $\Delta t=1 / f_{\text {samp }}, \mathrm{s}$ & $4 X 10^{-5}$ \\
Frequency step, $\Delta f=1 / T_{d}, \mathrm{~Hz}$ & 24.41 \\
Upper frequency limit, $f_{c}=1 /(2 \Delta t)=f_{\text {samp }} / 2, \mathrm{~Hz}$ & 12,500 \\
No. of frequencies, $L y=f_{c} / \Delta f=N p / 2$ & 512 \\
No. of independent samples & 200 \\
Overlap & 0 \\
Sample length, s & 8.192 \\
\hline \hline
\end{tabular}

\section{Cylindrical Duct Acoustic Modes}

For acoustic propagation in an infinite hard walled cylindrical duct with superimposed constant mean flow velocity $\vec{V}$, the pressure, $p=p(r, \theta, x, t)$ in cylindrical coordinates is found as a solution of the homogeneous convective wave equation,

$$
\frac{1}{c^{2}} \frac{\mathrm{D}^{2} p}{\mathrm{D} t^{2}}-\frac{\partial^{2} p}{\partial x^{2}}-\frac{1}{r} \frac{\partial}{\partial r}\left(r \frac{\partial p}{\partial r}\right)-\frac{1}{r^{2}} \frac{\partial^{2} p}{\partial \theta^{2}}=0
$$

where the substantive derivative is defined to be

$$
\frac{\mathrm{D}}{\mathrm{D} t}=\frac{\partial}{\partial t}+\vec{V} \frac{\partial}{\partial x}
$$

The general solution to equation (4), with or without mean flow, can be expressed as a linear combination of eigenfunctions,

$$
p(r, \theta, x, t)=\operatorname{Re}\left[\sum_{m=0}^{+\infty} \sum_{n=0}^{+\infty} A_{m, n}(x) \Psi_{m, n}(r, \theta) e^{-j \omega t}\right]
$$

where the eigenfunctions, $\Psi_{m, n}(r, \theta)$, of amplitude $A_{m, n}(x)$, will depend uniquely on the crosssectional shape of the duct. For the case of a hard walled cylindrical duct, the eigenfunction 


$$
\Psi_{m, n}(r, \theta)=J_{m}\left(k_{r, m, n} r\right) e^{j m \theta}
$$

An examination of equation (5) can be used to discuss the physics of the sound field in the duct. The eigenfunction is a mode shape which may be generated at a frequency $\omega$ in the $(r, \theta)$ plane perpendicular to the $x$-axis, and which may propagate as a travelling wave upstream or downstream in the duct in accordance with the $x$ dependent amplitude. The eigenvalues of this equation provide frequencies, "cut-off" frequencies, above which generated modes propagate unattenuated but below which excited modes exponentially decay. Several modes may coexist in the duct at a frequency of excitation, so long as this frequency is above their individual cut-off frequencies. The pressure in the duct is assumed to fluctuate harmonically as can be seen from the exponential time term, $e^{(-j \omega t)} \cdot k_{r, m, n}$ is the transverse eigenvalue of the $(m, n)^{t h}$ mode and is also called the transverse, combined radial-circumferential or simply the radial wavenumber.

According to equation (6), it can be seen that the normal modes are sinusoids in the circumferential direction and Bessel functions in the radial direction where $m$ specifies the circumferential mode number and $n$ indicates the associated radial mode number. The $(0,0)$ mode indicates the plane wave mode, $(1,0)$ the first circumferential (or azimuthal) mode and $(0,1)$ the first radial mode. Figure 10 gives an example of two mode shapes.
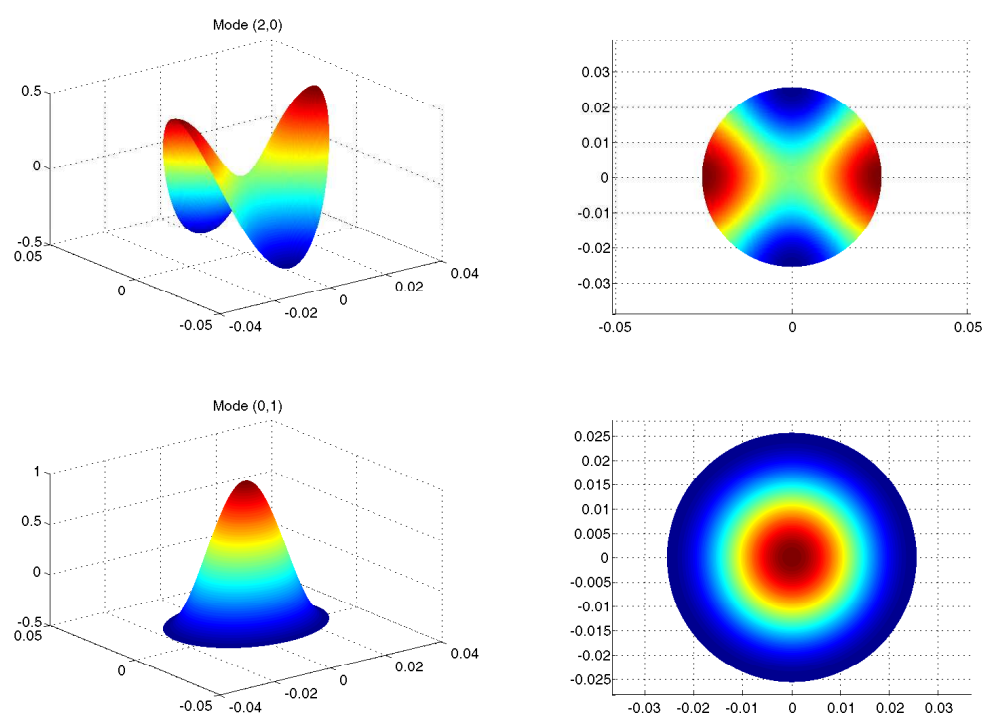

Figure 10. Acoustic Mode Shapes; $(2,0)$ and $(0,1)$ 


\section{Experimental Results}

An analysis was performed on the experimental rig of section B to detect the presence of non-linearities. As seen in figure 7, tonal interactions are more distinctive than broadband, and so tonal noise was emitted from the speaker when perfoming the diagnostic. In order to investigate this hypothesis that upstream noise might interact with a rotor/stator pair to produce acoustic energy at sum and difference frequencies, the experimental investigation had to be extended above the plane wave frequency region.

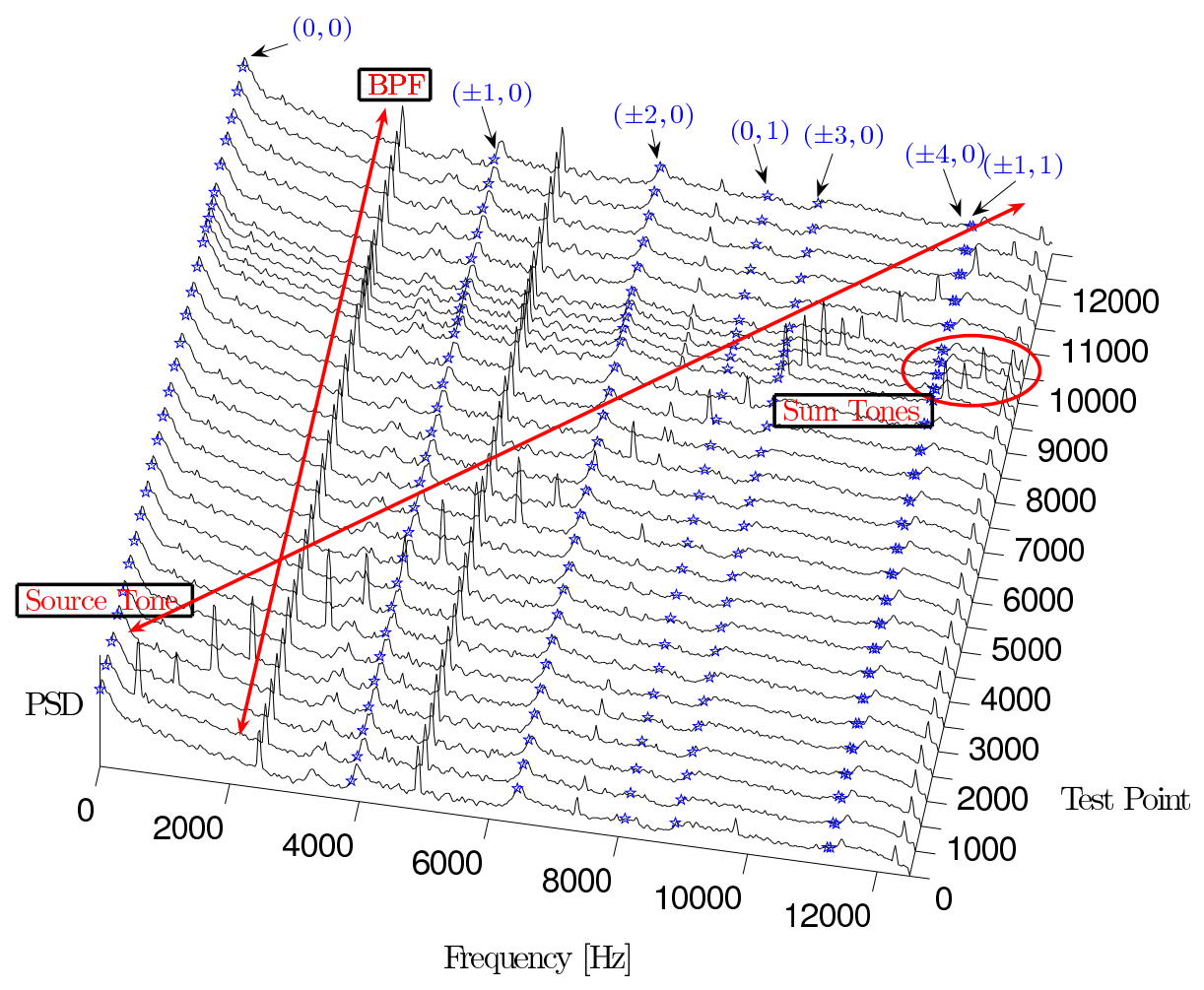

Figure 11. For microphone 5 only, the results of the investigation with and without the vane-axial fan turned on.

While varying the amplitude and frequency of the speaker signal, the power spectral density (PSD) of a microphone located downstream of the fan was examined. A set of tests was carried out where the speaker tone was incremented in steps of $500 \mathrm{~Hz}$ or $250 \mathrm{~Hz}$, from $500 \mathrm{~Hz}$ to $12.5 \mathrm{kHz}$. A waterfall plot of these results is shown in figure 11. The first averaged PSD in this plot is for the fan-only turned on. The fan has a high rotational speed of $16500 \mathrm{rpm}$ at the nominal max design voltage of 26VDC. As the fan has 8 blades this results in a blade pass frequency (BPF) of $2200 \mathrm{~Hz}$, a peak at which can be seen in figure 11 as are its harmonics, $\mathrm{nBPF}$, four of which are visible up to the Nyquist frequency.

With each successive test, the frequency from the speaker is increased. This plot is revealing as there is no indication of non-linear interaction until the speaker frequency reaches $8.75 \mathrm{kHz}$, above which only a sum tone with the BPF is detectable; e.g. a sum tone at 


\begin{tabular}{|c|cccccc|}
\hline $\mathrm{m}, \mathrm{n}$ & 0 & 1 & 2 & 3 & 4 & 5 \\
\hline 0 & 0 & 8102 & 14835 & 21512 & 28174 & 34827 \\
\pm 1 & 3893 & 11273 & 18050 & 24753 & 31430 & 38104 \\
\pm 2 & 6458 & 14180 & 21081 & 27849 & 34568 & 41255 \\
\pm 3 & 8884 & 16959 & 23991 & 30842 & 37615 & 44342 \\
\pm 4 & 11244 & 19628 & 26816 & 33757 & 40591 & 47366 \\
\pm 5 & 13566 & 22245 & 29577 & 36609 & 43508 & 50326 \\
\hline
\end{tabular}

Table 2. cut-off frequencies, $f_{m, n}^{c u t-o f f}$, $[\mathrm{Hz}]$, for $0.05115 \mathrm{~m}$ diameter cylindrical duct, $\mathbf{c}=\mathbf{3 4 0 \mathrm { m }} / \mathrm{s}$ and $\mathrm{M}=\mathbf{0 . 0 3 5}$.

$10.95 \mathrm{kHz}$ is visible which is the result of the addition of the the $\mathrm{BPF}(2.2 \mathrm{kHz})$ and the speaker tone $(8.75 \mathrm{kHz})$. Similar sum tones are to be seen in the figure as the speaker tone increases in frequency. In addition to sum frequencies, if the the model of figure 3(b) (i.e. a quadratic model) is to be respected, difference frequencies between the speaker tone and the BPF and its harmonics should also be measurable, e.g. a difference tone at $2400 \mathrm{~Hz}(\mathrm{BPF})-500 \mathrm{~Hz}($ Speaker $)=$ $1900 \mathrm{~Hz}$ should be present in figure 11. Figure 12 plots, as an example, the expected interactions for an upstream speaker tone of $9.3 \mathrm{kHz}$ with the $\mathrm{nBPF}$ frequencies assuming a quadratic model. The lowest difference tone to be seen is at $300 \mathrm{~Hz}=$ $9600 H z(4 \mathrm{xBPF})-9300 H z($ speaker $)$ for example. To help understand why there is a disparity between the interaction frequencies measured in figure 11 and those expected,

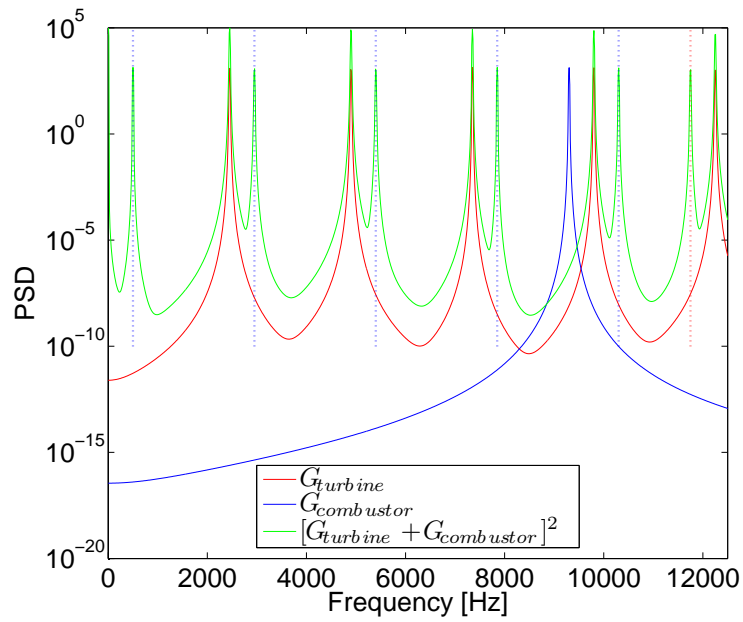

Figure 12. Simulated data representing a quadratic interaction between the turbine and combustor, with a BPF of $2400 \mathrm{~Hz}$ and a combustor frequency of $9.3 \mathrm{kHz}$. the cut-off frequencies for the higher modes in the duct were calculated. These values are given in table 2 for this diameter duct and the relevant values are superimposed onto the waterfall plot (black stars). It can be seen clearly how the interaction tone appears only above $\approx 11200 \mathrm{~Hz}$, which is either the $( \pm 4,0)$ cut-off frequency or the $( \pm 1,1)$ cut-off frequency. It was posited therefore, that the interaction tone has a modal structure of either $(+4,0),(-4,0),(+1,1)$ or $(-1,1)$, or possibly some combination of these. In addition, it is suggested that this modal structure comes about as a result of the interaction of the modal structure of the BPF frequency with that of the speaker frequency. A modal decomposition of the pressure field upstream and downstream 
of the fan was performed by Bennett ${ }^{19}$ which showed the modal content of the interaction tone downstream of the fan to be of the form $(+4,0)$. It seems likely therefore, that the non-linear term $[\operatorname{Comb}(t)+\text { Turbine }(t)]^{2}$ plotted in figure 12, needs to be used in conjunction with duct modal theory. That is to say, if energy at two frequencies interact to create energy at a third, then this energy will only propagate down the duct if the mode which carries it is above its cut-off frequency.

\section{E. Non-Linear Identification Techniques}

From the simulations of section A, identification of the non-linear contribution to a measurement downstream of either the vane-axial fan of the small-scale experiment or a turbine of an aero-engine should be quite straight forward. Measurements of the individual linear contributions, viz. the combustion noise and the turbine noise could be added and squared in the time domain and this input conditioned from the downstream measurement. Unfortunately, with regard to the rig, although an isolated measurement of the speaker noise is possible indirectly, via the electrical supply signal to the speaker, no means of measuring the vane-axial fan noise alone is readily available. The model of figure 13 represents the physical situation in the duct. In the figure, the two principle acoustic inputs into the duct are the combustion (speaker) noise and the vane-axial turbine (vane-axial fan) noise. $\mathrm{x}(\mathrm{t})$ is an upstream measurement, whereas $\mathrm{y}(\mathrm{t})$ is a measurement downstream of the fan. The downstream measurement, $\mathrm{y}(\mathrm{t})$, will always contain the sum of the linear parts in addition to the non-linear component, when present, whereas the upstream measurement, $\mathrm{x}(\mathrm{t})$, will be comprised of the source noise as well as the fan noise and the non-linear contribution (when present) depending on the conditions for back propagation. As a consequence of this, the model of figure 13 can be simplified to figure 14, where the second, non-linear, component is included when the physics dictates. An example can be given with reference to figure 11, where the downstream measurement, in this case, is linear until the speaker signal is raised above $8.75 k \mathrm{~Hz}$, above which the second, non-linear term needs to be included. The difficulty therefore, is to separate the non-linear part from the linear part when the non-linear part is present.

The model presented in figure 15 facilitates this linear/non-linear decomposition, when the underlying non-linear phenomenon is quadratic in nature. Squaring the input $\mathrm{x}(\mathrm{t})$ results in the following expansion

$$
\left((C+F)+(C+F)^{2}\right)^{2}=\underline{C^{2}+2 C F+F^{2}}+6 C^{2} F+6 C F^{2}+4 C^{3} F+6 C^{2} F^{2}+4 C F^{3}+2 C^{3}+2 F^{3}+C^{4}+F^{4}
$$

when the non-linear component is present. As can be seen from the right-hand-side; the first three terms are the expansion of the non-linear part whereas the linear parts, i.e., C 
and F, do not appear. Therefore a coherence between the square of the input with the output should isolate the non-linear part of the output only. This technique was applied to the data presented in section $\mathrm{D}$ and the result is shown in figure 16 . As can be seen, the coherence is $\approx 0$ apart from at the interaction tones above $11200 \mathrm{~Hz}$, and at some of the $\mathrm{nBPF}$ frequencies. In addition, some non-linear interaction is seen to take place between the shaft imbalance and the $\mathrm{nBPF}$ frequencies, with some sum and difference frequencies around the $\mathrm{nBPF}$ frequencies identified. The shaft imbalance, $\frac{B P F}{\text { no.ofblades }}=2200 / 8=275 \mathrm{~Hz}$, is non-acoustic, and thus these peaks, along with the nBPF peaks appearing in figure 16 are thought to present as a result of the microphones sensitivity to vibration.

With reference to figure 15, figure 16 shows how the non-linear contribution to the downstream measurement may be isolated by examining the coherence between the square of the upstream measurement and the downstream measurement. In order to isolate the linear contribution (in the presence of non-linear interactions), partial coherence techniques as discussed in Bendat and Piersol ${ }^{12}$ and employed by Rice and Fitzpatrick ${ }^{20}$ may be used.

Pertinent to this problem are results where it is calculated that if two arbitrary signals, $i$ and $j$, are composed of at least two components each, where $r$ is one of them, then the cross-spectrum between $i$ and $j$ with the linear effects of $r$ removed can be expressed as

$$
G_{i j \cdot r}=G_{i j}-\frac{G_{i r} G_{r j}}{G_{r r}}
$$

It can be seen from this equation that the part correlated with $r$ must then be

$$
G_{i j: r}=\frac{G_{i r} G_{r j}}{G_{r r}}
$$

For $i=j$, the autospectrum of either $i$ or $j$ with the linear part of $r$ removed can be written as

$$
G_{i i \cdot r}=G_{i i}-\frac{G_{i r} G_{r i}}{G_{r r}}
$$

with the correlated part given by

$$
G_{i i: r}=\frac{\left|G_{r i}\right|^{2}}{G_{r r}}
$$

The partial coherence function between $i$ and $j$ with the linear effects of $r$ removed, as derived in Bendat and Piersol, ${ }^{12}$ may now be defined as the ordinary coherence function between the conditioned spectra;

$$
\gamma_{i j \cdot r}^{2}=\frac{\left|G_{i j \cdot r}\right|^{2}}{G_{i i \cdot r} G_{j j \cdot r}}
$$


In summary, for the arbitrary signals $i$ and $j$ above, the non-linear and linear contributions to the coherence function can be given as

$$
\begin{aligned}
\text { Nonlinear Coherence } & =\gamma_{\left(i^{2}, j\right)}^{2} \\
\text { Linear Coherence } & =\gamma_{(i, j) \cdot i^{2}}^{2}
\end{aligned}
$$

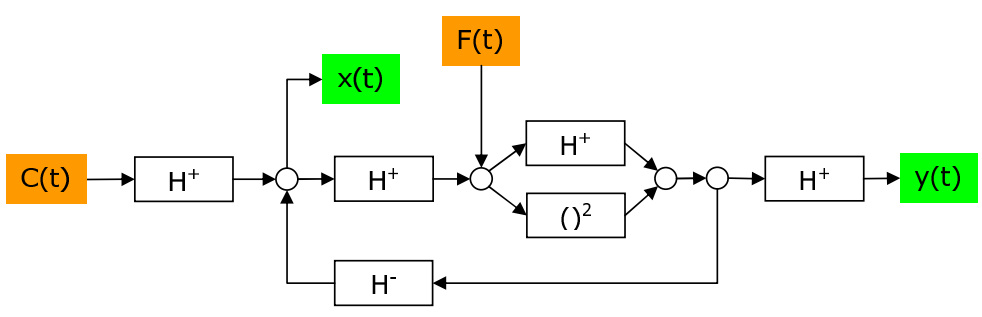

Figure 13. Actual schematic for upstream and downstream measurements. Fan noise and interaction noise is propagated upstream to upstream measurement position

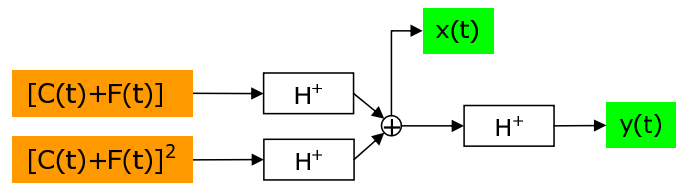

Figure 14. Inputs into upstream and downstream measurements can be modelled as having linear and nonlinear parts.

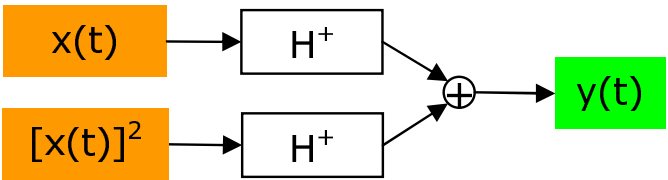

Figure 15. Input/output model for non-linear decomposition

\section{Full Scale Engine Tests}

\section{A. Introduction}

The non-linear identification techniques, developed with the experimental rig, were applied to data from full scale turbo-fan engine tests. A Rolls-Royce engine was instrumented with pressure transducers at the combustor can and in the hot jet pipe, and microphones were placed in the near-field. A schematic of some of the instrumentation is shown in figure 17. RP1 was located in the combustor outer casing whilst RP3 was located within the combustor. RP1 and the hot-jet sensor, RPB, were flush mounted, while RP3 was positioned at the outer end of an igniter tube to avoid the high temperatures within the combustor. The sensors were manufactured by Vibro-meter and have been proven to have high frequency and temperature capabilities. Microphone 5 (M5) was located $10.04 \mathrm{~m}$ from the jet axis and hence clear of the hydrodynamic turbulent pressure fluctuations of the jet. The results from five steady- 


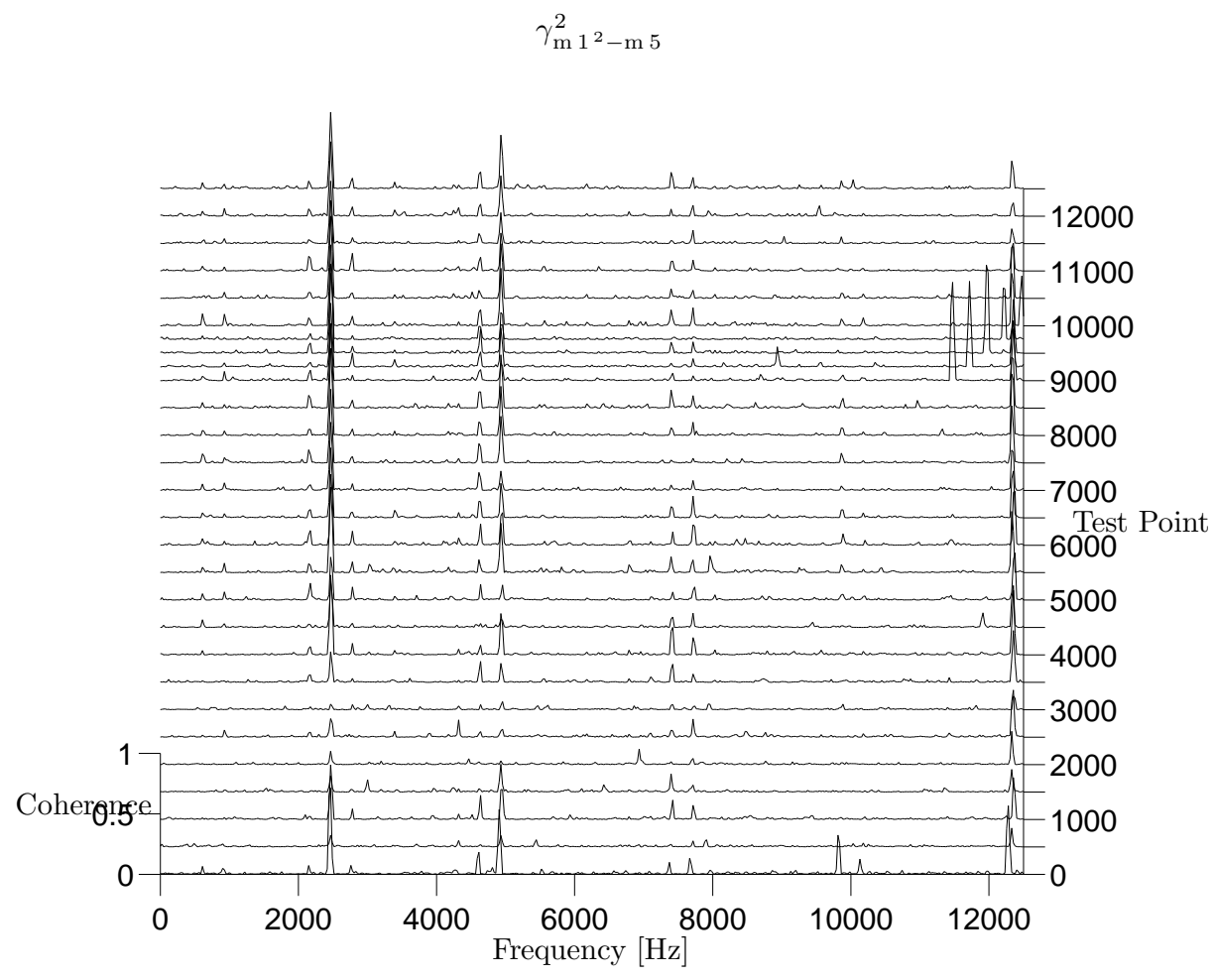

Figure 16. The coherence between the square of an upstream measurement, M1, with a downstream signal, M5, is calculated for the same test points as those in figure 11.

state points (engine power settings), were examined. The power settings defined for the test included some diagnostic conditions that are not necessarily representative of operational conditions.

Table 3. Spectral estimate parameters

\begin{tabular}{lc}
\hline \hline Parameter & Value \\
\hline Segment length, i.e., data points per segment, $N p$ & 8192 \\
Sample rate, $f_{\text {samp }}$, samples $/ \mathrm{s}$ & 32768 \\
Segment length, $T_{d}=N p / f_{\text {samp }}, \mathrm{s}$ & 0.25 \\
Sampling interval, $\Delta t=1 / f_{\text {samp }}, \mathrm{s}$ & $3.0518 X 10^{-5}$ \\
Frequency step, $\Delta f=1 / T_{d}, \mathrm{~Hz}$ & 4 \\
Upper frequency limit, $f_{c}=1 /(2 \Delta t)=f_{\text {samp }} / 2, \mathrm{~Hz}$ & 16384 \\
No. of frequencies, $L y=f_{c} / \Delta f=N p / 2$ & 4096 \\
No. of independent samples & 400 \\
Overlap & 0.75 \\
Sample length, s & 100 \\
\hline \hline
\end{tabular}

For the highest of the five test points, the PSD of the hot-jet pipe transducer, $R P B$, is 20 of 26

Dr. G. Bennett and Prof. J. Fitzpatrick 
shown in figure 18. A number of interesting points can be noted in this figure. Firstly, a tone in the combustor can is generated at $\approx 500 \mathrm{~Hz}$. This tone is of sufficiently high amplitude as to generate superharmioncs. The tone and the superharmonics are measurable downstream of the turbine. Secondly, a tone generated from rotor/stator interaction in the high pressure turbine is measurable downstream of the low pressure turbine near the exit plane. Thirdly, the combustion tone and its superharmonics interact with this HPT tone in a non-linear fashion similar to that observed with the experimental rig: sum and difference frequencies are formed due to combustion noise impinging on a rotor/stator pair. It is most significant, that not only does this interaction occur, but that the interaction tones along with the HPT tone and the combustor tones are able to propagate through the circuitous path created by the various stages of the turbines.

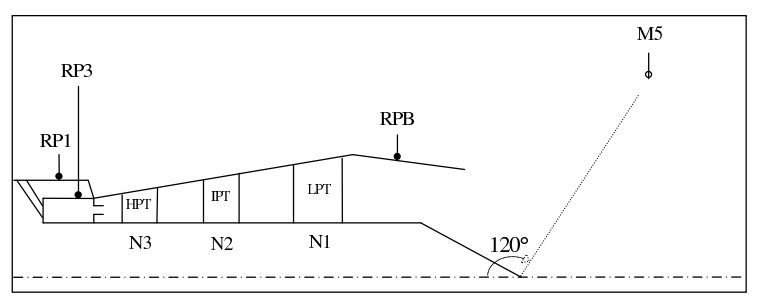

Figure 17. Engine instrumentation schematic with location of external farfield microphone.

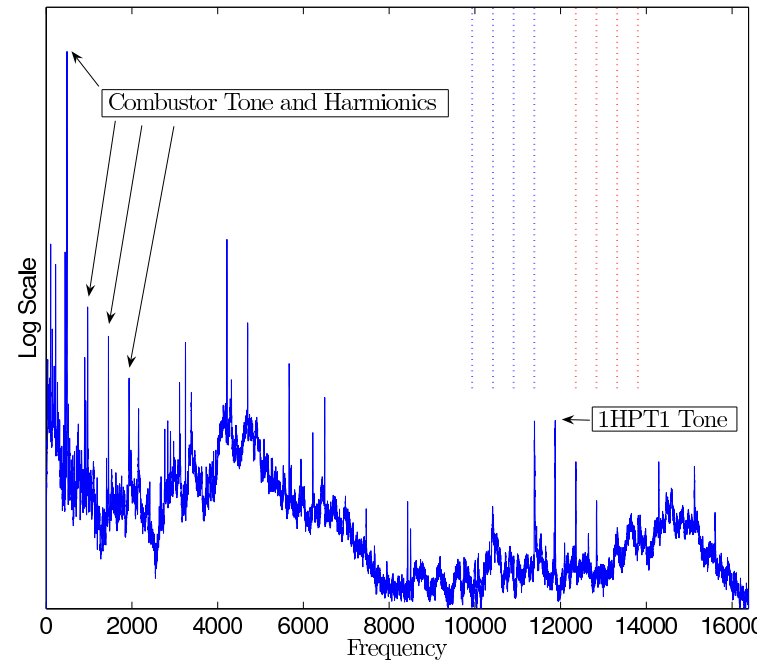

Figure 18. PSD at sensor location in the hot-jet pipe (RPB) for a particular engine power. A combustor tone at $\approx 500 \mathrm{~Hz}$ is measured as well as superharmonics. A HPT tone, propagated through the turbine is also measured. To be seen on either side of this tone is energy at sum and difference frequencies.

\section{B. Non-linear Analysis}

Typically, as previously discussed, in order to investigate, in a causal way, the relationship between combustion noise and a downstream measurement, the coherence function is used. A waterfall plot of the coherence function between the combustion can sensor RP1 and the hot-jet pipe sensor RPB for the five test-points is presented in figure 19. The plot is annotated to highlight the HPT tone, which is measured at all test-points, and the combustor tone and harmonics in addition to the sum and difference frequencies, which are measured 
at the highest point only. Only careful scrutiny and knowledge of rotor vane numbers would allow these peaks to be identified from the many tones to be found in a nearfield aero-engine spectrum. Figure 20 shows the same waterfall plot but in this case the coherence has been calculated between the square of the combustor can measurement and that of the hot-jet pipe sensor. It is immediately evident from this plot that non-linear interaction has taken place at the higher test point and that peaks would be expected in the spectrum which would not be accountable from linear noise source superposition.

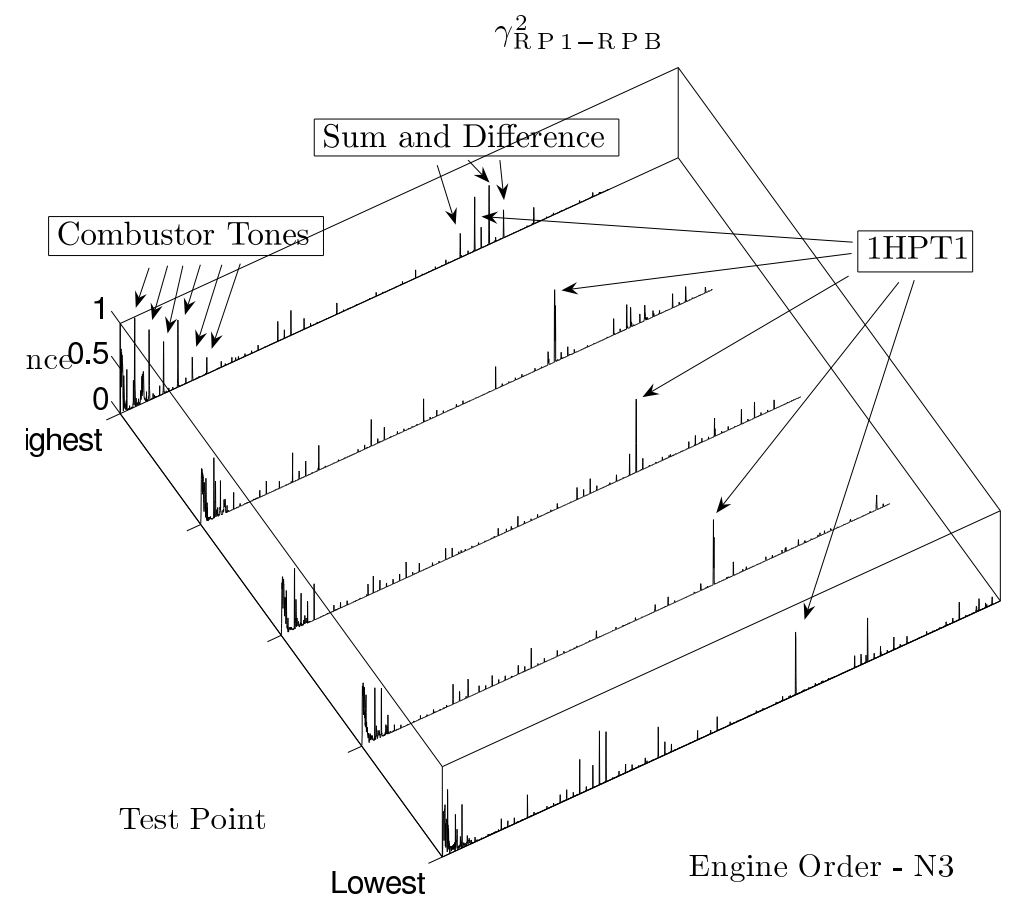

Figure 19. The coherence between the combustion can sensor RP1 and the hot-jet pipe sensor RPB for five increasing power test points.

In addition to being a tool for non-linear interaction identification, this quadratic analysis approach can be used, as explained in section E, to separate the non-linear contribution to the spectrum from the linear part. The model of figure 15 was used and the full scale test data processed with the following equations;

$$
\begin{aligned}
\text { Nonlinear COP } & =\gamma_{\left(R P 1^{2}, R P B\right)}^{2} G_{(R P B, R P B)} \\
\text { Linear COP } & =\gamma_{(R P 1, R P B) \cdot R P 1^{2}}^{2} G_{(R P B, R P B) \cdot R P 1^{2}}
\end{aligned}
$$

Figure 21 shows the standard COP calculated between the combustor can location and the hot-jet pipe location. This coherence function of plot $\mathrm{B}$, in conjunction with the COP in red in figure A, would be used, for example, to assess the frequency range for which acoustic treatment might be designed to reduce combustion noise radiation to the farfield. 


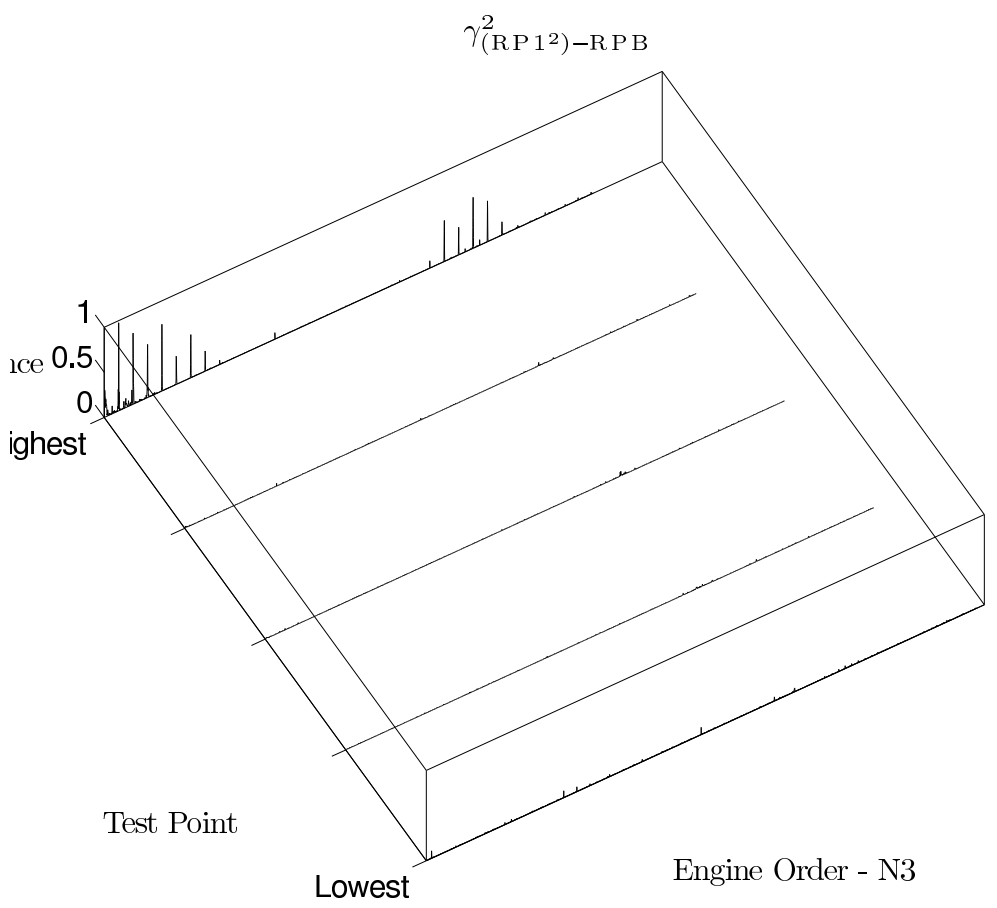

Figure 20. The coherence between the square of the combustion can sensor RP1 and the hot-jet pipe sensor RPB for five increasing power test points. Non-linear interaction is seen to be present only at the highest test-point.

However, as figure 22 displays, the frequency range that the non-linear contribution spans is far greater than that attributable to the actual sound source, as plotted in figure 23. As it is difficult to design acoustic treatment to absorb sound over a large frequency range, the ability to identify the non-linear contribution means that efforts can be divided into two parts; a). absorption or reduction of the (linear) combustion noise, ideally upstream of the turbine, and, b). tackling the non-linear interaction process separately. Obviously, if the combustion noise is reduced upstream of the turbine, then, as highlighted in the simulations, the contribution of the non-linear noise is greatly diminished.

This analysis was applied to the frequency range around the 1HPT1 tone also, and successfully identified the sum and difference tones as well as subtracting them from the COP, decomposing it into linear and non-linear parts.

\section{Conclusions}

In this paper, the ability for coherence based noise source identification techniques to identify core noise in aero-engines was discussed. An experimental rig was designed and built to gain a fundamental physical understanding of the propagation of noise through a rotor/stator set-up. Experiments performed on the rig allowed it to be shown experimentally that acoustic energy in a duct at a certain frequency may interact with rotor/stator noise at a 

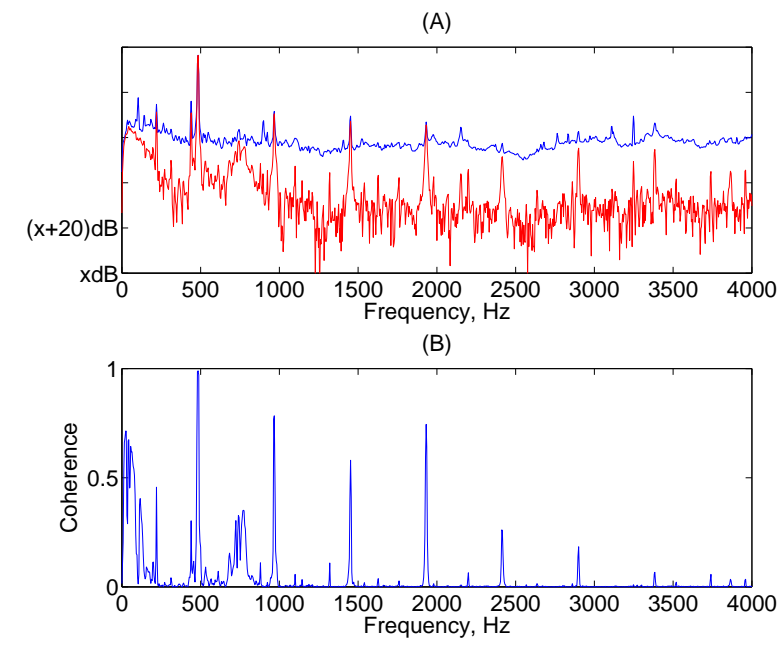

Figure 21. Plot B shows the coherence between the combustion can sensor RP1 and the hot-jet pipe sensor RPB. Only the frequency range $0-4 \mathrm{kHz}$ is displayed. In plot A the PSD of $\mathrm{RPB}$ is compared to the coherent output power using the coherence of plot $\mathrm{B}$.
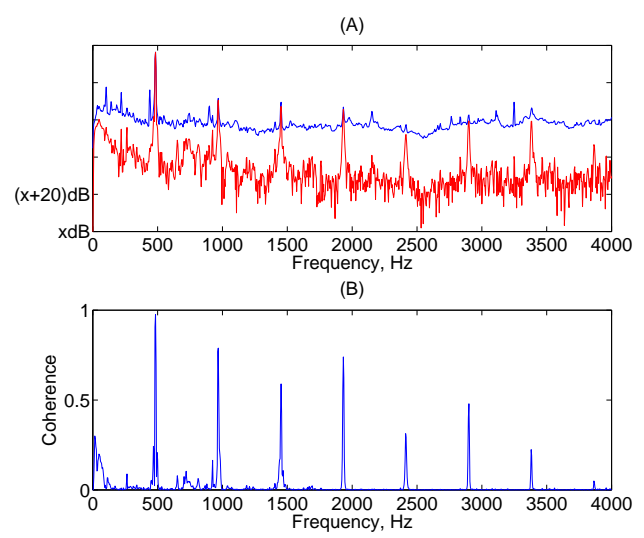

Figure 22. The non-linear part of the COP is plotted versus the PSD of RPB
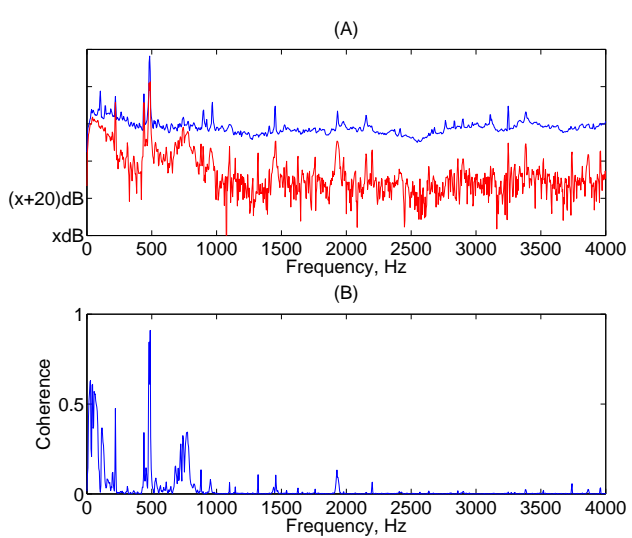

Figure 23. The linear part of the COP is plotted versus the PSD of RPB 
different frequency to scatter energy to a third frequency which is a sum of the two. The case where broad band or narrow band noise, such as may originate from a combustor, as opposed to an upstream rotor, interacts with a rotor-stator pair, (e.g. turbine noise), producing noise at sum and difference frequencies was explored in this paper. An experimental technique was developed which enables the non-linear interaction between the propagated sound source with the vane-axial fan to be detected and identified when present. The technique was extended to allow the linear and non-linear acoustic contributions to be separated. From analysis of data from full scale turbo-fan engine tests scattering was seen to occur between the combustion noise and the high pressure turbine which was measurable in the hot jet pipe after propagation through the many turbine stages. The techniques allowed the non-linear interaction to be successfully identified and linear and non-linear coherent output powers to be determined.

\section{Acknowledgements}

This work was partly supported by the $\operatorname{SILENCE}(\mathrm{R})$ project which is funded under EU Commission contract no. G4RD-CT-2001-00500

\section{References}

${ }^{1}$ Karchmer, A. M. and Reshotko, M., "Core noise source diagnostics on a turbofan engine using correlation and coherence techniques," Tech. Rep. TM X-73535, NASA, 1976.

${ }^{2}$ Karchmer, A. M., Reshotko, M., and Montegani, F. J., "Measurement of far field combustion noise from a turbofan engine using coherence function," AIAA 4th Aeroacoustics Conference, No. AIAA-77-1277, Atlanta, Georgia, October 3-5 1977.

${ }^{3}$ Reshotko, M. and Karchmer, A. M., "Core noise measurements from a small general aviation turbofan engine," Tech. Rep. TM81610, NASA, 1980.

${ }^{4}$ Halvorsen, W. G. and Bendat, J. S., "Noise Source Identification Using Coherent Output Power Spectra," Sound and Vibration, Vol. 9, No. 8, 1975, pp. 15, 18-24.

${ }^{5}$ Karchmer, A. M., "Conditioned pressure spectra and coherence measurements in the core of a turbofan engine," Tech. Rep. TM82688, NASA, 1981, AIAA Paper 81-2052.

${ }^{6}$ Shivashankara, B. N., "High bypass ratio engine noise component separation by coherence technique," AIAA 7th Aeroacoustics Conference, No. AIAA-81-2054, Palo Alto, October 5-6 1981.

${ }^{7}$ Shivashankara, B. N., "High bypass ratio engine noise component separation by coherence technique," Journal of Aircraft, Vol. 23, No. 10, 1986, pp. 763-767.

${ }^{8}$ Chung, J. Y., "Rejection of flow noise using a coherence function method," J. Acoust. Soc. Am., Vol. 62, No. 2, 1977, pp. 388-395.

${ }^{9} \mathrm{Hsu}$, J. S. and Ahuja, K. K., "A coherence-based technique to separate ejector internal mixing noise from farfield measurements," AIAA/CEAS 4th Aeroacoustics Conference, No. AIAA-98-2296, June 2-4 1998.

${ }^{10}$ Minami, T. and Ahuja, K. K., "Five-microphone method for separating two different correlated noise 
sources from farfield measurements contaminated by extraneous noise," AIAA/CEAS 9th Aeroacoustics Conference, No. AIAA-03-3261, South Carolina, May 12-14 2003.

${ }^{11}$ Bennett, G. J. and Fitzpatrick, J. A., "A comparison of coherence based acoustic source identification techniques," 12th International congress on sound and vibration, No. 950, Lisbon, Portugal, 11-14 July 2005.

${ }^{12}$ Bendat, J. S. and Piersol, A. G., Random Data: Analysis and Measurement Procedures, John Wiley \& Sons, 1986.

${ }^{13}$ Siller, H. A., Arnold, F., and Michel, U., "Investigation of Aero-Engine Core-Noise Using a Phased Microphone Array," 7th AIAA/CEAS Aeroacoustics Conference, No. AIAA-2001-2269, Maastricht, The Netherlands, 28-30 May 2001.

${ }^{14}$ Cumpsty, N. A., "Sum and difference tones from turbomachines," Journal of Sound and Vibration, Vol. 32, No. 3, 1974, pp. 383-386.

${ }^{15}$ Holste, F. and Neise, W., "Noise Source Identification in a Propfan Model by Means of Acoustical Near Field Measurements," Journal of Sound and Vibration, Vol. 203, No. 4, 1997, pp. 641-665.

${ }^{16}$ Enghardt, L., Tapken, U., Neise, W., Kennepohl, F., and Heinig, K., "Turbine Blade/Vane Interaction noise: acoustic mode analysis using in-duct sensor rakes," 7th AIAA/CEAS Conference on Aeroacoustics., No. AIAA-2001-2153, Maastrict, The Netherlands., May 2001.

${ }^{17}$ Nallasamy, M., Hixon, R., Sawyer, S., Dyson, R., and Koch, L., "A Time Domain Analysis of GustCascade Interaction Noise," 9th AIAA/CEAS Aeroacoustics Conference and Exhibit, No. AIAA-2003-3134, Hilton Head, South Carolina, May 12-14 2003.

${ }^{18}$ Moore, C. J., "In-duct investigation of subsonic fan "rotor-alone" noise." J. Acoust. Soc. Am., Vol. 51, 1972, pp. 1471-1482.

${ }^{19}$ Bennett, G. J., Noise Source Identification For Ducted Fans, Ph.D. thesis, Trinity College Dublin, 2006.

${ }^{20}$ Rice, H. J. and Fitzpatrick, J. A., "A generalised technique for spectral analysis of non-linear systems." Mechanical Systems and Signal Processing, Vol. 2, No. 2, 1988, pp. 195-207. 